\title{
Differential temperature effects on photoperiodism in female voles: An explanation for species-specific declines in vole populations
}

\author{
Laura van Rosmalen ${ }^{1}$, Bernd Riedstra ${ }^{2}$, Nico Beemster ${ }^{3}$, Cor Dijkstra ${ }^{4}$, and Roelof Hut ${ }^{4}$ \\ ${ }^{1}$ University of Groningen \\ ${ }^{2}$ Groningen Institute for Evolutionary Life Sciences \\ ${ }^{3}$ Altenburg \& Wymenga Ecological Consultants \\ ${ }^{4}$ Rijksuniversiteit Groningen
}

November 29, 2021

\begin{abstract}
Many mammalian species use photoperiod as a predictive cue to time seasonal reproduction. In addition, metabolic effects on the reproductive axis may also influence seasonal timing, especially in female small, short-lived mammals. To get a better understanding of how annual cycling environmental cues impact reproductive function and plasticity in small, short-lived herbivores with different geographic origins, we investigated the mechanisms underlying integration of temperature in the photoperiodicaxis regulating female reproduction in a Northern vole species (tundra vole, Microtus oeconomus) and in a Southern vole species (common vole, Microtus arvalis). We show that photoperiod and temperature interact to determine appropriate physiological responses; there is species-dependent annual variation in the sensitivity to temperature for reproductive organ development. In common voles, temperature can overrule photoperiodical spring-programmed responses, with reproductive organ mass being higher at $10^{\circ} \mathrm{C}$ than at $21^{\circ} \mathrm{C}$, whereas in autumn they are less sensitive to temperature. These findings are in line with our census data, showing an earlier onset of spring reproduction in cold springs, while reproductive offset in autumn is synchronized to photoperiod. The reproductive organs of tundra voles were relatively insensitive to temperature, whereas hypothalamic gene expression was generally upregulated at $10^{\circ} \mathrm{C}$. Thus, both vole species use photoperiod, whereas only common voles use temperature as a cue to control spring reproduction, which indicates species-specific reproductive strategies. Due to global warming, spring reproduction in common voles will be delayed, perhaps resulting in shorter breeding seasons and thus declining populations, as observed throughout Europe.
\end{abstract}

\section{Hosted file}

temp females (MS) Mol Ecol.pdf available at https://authorea.com/users/448518/articles/ 547320-differential-temperature-effects-on-photoperiodism-in-female-voles-an-

explanation-for-species-specific-declines-in-vole-populations 